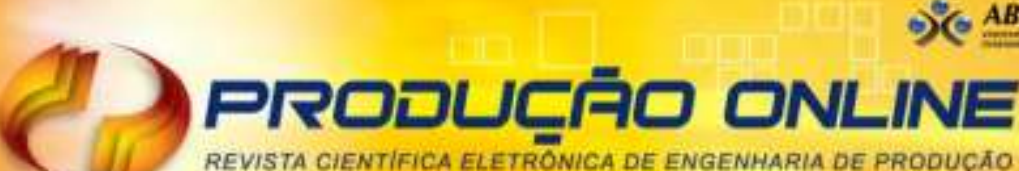 REVISTA CIENTIFICA ELETRÓNICA DE ENGENHARIA DE PRODUCATO ISSN 1676-1901
}

\section{ANÁLISE DE EFICIÊNCIA ENERGÉTICA PARA INDÚSTRIA TÊXTIL: UM ESTUDO DE CASO EM UMA EMPRESA DE MINAS GERAIS}

\section{ANALYSIS OF ENERGY EFFICIENCY FOR TEXTILE INDUSTRY: A CASE STUDY IN A MINAS GERAIS COMPANY}

\author{
Paloma Yara Guimarães da Torre*E-mail: palomagtorre@hotmail.com \\ Jean Carlos Machado Alves* E-mail: jean.mep@gmail.com \\ Savio Figueira Corrêa* E-mail: savio.ufop@gmail.com \\ *Universidade Federal de Ouro Preto (ICEA/UFOP), João Monlevade, MG
}

\begin{abstract}
Resumo: As transformações pela qual passa o clima mundial, atribuídas à forte influência antropológica na natureza, têm chamado a atenção da sociedade para a necessidade de melhor gestão dos recursos naturais e energéticos. $\mathrm{O}$ artigo tem por objetivo realizar uma análise visando a Eficiência Energética para uma indústria têxtil mineira que enfrenta sérios problemas devido às consequências trazidas pela crise hídrica. Por meio de análises e visitas de campo, foi possível propor a introdução de indicadores de Eficiência Energética para melhor controle do custo benefício da energia elétrica consumida. Tendo por base a cultura da organização, foi sugerida a introdução do modelo conhecido como Ecoeficiência, assim como a instalação de uma usina de geração de energia solar fotovoltaica própria, de modo a atender à demanda por energia elétrica da fábrica de forma limpa, renovável e economicamente viável.
\end{abstract}

Palavras chave: Eficiência Energética. Ecoeficiência. Geração fotovoltaica. Sustentabilidade empresarial.

Abstract: Abstract: Transformations in which passes the global climate, attributed to the strong anthropological influence in nature, have attracted the attention of the society to the need of better use of natural resources and energy. Sustainability Engineering seeks to promote an economic development model in order to generate the least possible impact in the environment. This article aims to create a model of energy for a mining textile industry facing serious problems due to the consequences brought about by the water crisis. Through analysis and field visits, it was possible to propose the introduction of energy efficiency indicators to better control the cost benefit of the electricity consumed. Based on the culture of the organization, it was suggested the introduction of the model known as Eco-efficiency, as well as the installation of a plant for its own photovoltaic solar power generation in order to meet the demand for cleanly, renewable and economically practicable electric energy.

Keywords: Energy Efficiency. Eco-efficiency.,Photovoltaic generation. Corporate sustainability.

\section{INTRODUÇÃO}

A energia é o fenômeno presente no funcionamento de todos os sistemas do universo e responsável pelos processos de transformações físicos, químicos e biológicos. Ela é fundamental para a realização das atividades vitais à sociedade moderna e por isso tem enorme importância na economia mundial (CRETON; STHEL, 2011). 
Observa-se a necessidade da gestão cada vez mais eficiente dos recursos energéticos, esses que são importantes e essenciais à nossa sobrevivência, o que torna relevante as reflexões no campo da engenharia.

O uso abusivo dos recursos naturais desencadeou uma série de problemas ambientais, o que tem chamado atenção de parte da sociedade para esta realidade. De acordo com o Intergovernmental Panel on Climate Change - IPCC (2016), cerca de 50 mil pessoas de mais de 195 nações se reuniram em Paris em 2015 na Conferência do Clima a fim de discutir formas de combater as transformações pelas quais passa o clima mundial. Acredita-se que tais mudanças são consequência da forte interferência antropológica na natureza, portanto, se faz necessária uma melhor gestão destes recursos nos âmbitos econômico e social.

No que tange ao consumo de insumos naturais, o setor industrial é um dos maiores consumidores energéticos e com grandes potencialidades de provocar danos ao meio ambiente, seja por meio do processo produtivo ou pela fabricação de produtos poluentes, cuja destinação final é inadequada. Segundo a EPE (2016), em 2015 a classe industrial foi responsável por $36,3 \%$ do consumo de energia no Brasil.

Apesar do crescente impacto ambiental, as indústrias começaram a se preocupar com ações de desenvolvimento sustentável e eficiência energética, principalmente após o aumento das tarifas de energia elétrica e períodos de escasses de água (TONIM, 2009).

Em uma realidade mais específica, na região do Médio Piracicaba em Minas Gerais tem-se uma grande indústria do setor têxtil com mais de 130 de operação, a qual tem enfrentado sérios problemas devido a um aumento substancial em seus custos com energia elétrica, o que encadeou uma série problemas de planejamento e controle da produção.

Assim, o presente artigo tem por objetivo analisar a viabilidade da instalação de uma central de geração fotovoltaica como alternativa para eficiência energética em uma indústria têxtil de grande porte, considerando o contexto da Engenharia da Sustentabilidade.

Em face do problema enfrentado por essa organização específica, mas comum a muitas outras, surge a necessidade de desenvolver modelos de eficiência energética e de recursos naturais a fim de combinar interesses econômicos e socioambientais, visando o desenvolvimento sustentável das nações. 


\section{REVISÃO DE LITERATURA}

De acordo com Rego (2013), a Revolução Industrial, com início na Inglaterra no século XVIII, trouxe mudanças econômicas e sociais, tendo se internacionalizado no século XIX. As novas técnicas industriais utilizavam de um volume bem maior de matérias primas, visando exclusivamente o crescimento econômico de alguns países.

Os recursos naturais, antes utilizados somente para a sobrevivência e confecção de artesanatos, serviram como matéria prima e fonte de energia para mover as máquinas e impulsionar a produção. Segundo Creton e Sthel (2011), a invenção da máquina a vapor, movida a princípio por madeira e carvão, foi o grande marco da utilização da energia pelo homem. Desde então, a energia útil em larga escala começou a ser explorada.

Goldemberg e Lucon (2011) e Creton e Sthel (2011) definem energia como a capacidade de produzir trabalho. Enquanto que trabalho é entendido como o resultado de uma força sobre o deslocamento de um corpo. Uma definição mais clássica foi dada por Maxwell em 1872: "energia é aquilo que permite uma mudança na configuração de um sistema, em oposição a uma força que resiste a essa mudança" (HALLIDAY et al, 2009, p.178).

Pode-se ainda denominar a energia de acordo com a fenomenologia física. Por exemplo, a energia é classificada em energia luminosa de acordo com os conceitos termodinâmicos, quando se fala de radiação e calor; potencial gravitacional, quando se trata da energia armazenada por um corpo devido à sua altura; cinética, relacionada ao movimento dos corpos; potencial elástica, referente à deformação de um corpo; energia potencial química, aquela armazenada nas ligações químicas do corpo; nuclear, que é a energia de ligação dos núcleos atômicos; eletromagnética, relacionada à presença dos campos elétrico e magnético (CRETON; STHEL, 2011).

De acordo com Goldemberg e Lucon (2011), a produção de eletricidade é responsável por mais de $20 \%$ do consumo de energia primária mundial e a produção a partir dos combustíveis fósseis é a que predomina. O princípio geral da geração de energia elétrica é basicamente o mesmo, independente da fonte: um gerador eletromagnético rotativo é acionado mecanicamente. Esse acionamento mecânico é conseguido de diferentes formas, de acordo com a natureza da usina geradora (REIS; SANTOS, 2014). 
A energia pode ser encontrada na natureza por meio de fontes renováveis e não renováveis. As energias renováveis são aquelas cuja fonte é proveniente dos ciclos naturais de conversão da radiação solar, fonte de quase toda energia primária da Terra, e são quase sempre inesgotáveis. As fontes não renováveis são aquelas esgotáveis, as quais demoram milhões de anos para se formarem na natureza, tais como minas de carvão e petróleo (SANTOS, 2015). A Tabela 01 apresenta as principais formas de geração de energia e classifica-as quanto à natureza da fonte.

Tabela 01 - Fontes renováveis e não renováveis
\begin{tabular}{|ll|}
\hline Fonte & Classificação \\
\hline \hline Biomassa & Renovável \\
Carvão Mineral e Derivados & Não renovável \\
Eólica & Renovável \\
Gás Natural & Não renovável \\
Geotérmica & Renovável \\
Hidráulica & Renovável \\
Oceânica & Renovável \\
Petróleo e Derivados & Não renovável \\
Solar & Renovável \\
Urânio e Derivados & Não renovável \\
\hline
\end{tabular}

Fonte: Santos (2015)

Segundo a EPE (2016), 76\% da oferta interna de energia no Brasil são provenientes de fontes renováveis. Esse índice é um dos mais altos do mundo, considerando uma média mundial de $14 \%$, chegando a $6 \%$ nos países desenvolvidos. Entretanto, o Brasil ainda possui grande potencial de expansão das renováveis, já que dispõem de clima favorável, grandes extensões litorais, disponibilidade de mão de obra e amplo espaço territorial.

Dados apresentados pela Figura 1 mostram a distribuição da matriz energética do Brasil em 2015. 
Figura 01 - Distribuição da matriz energética brasileira em 2015

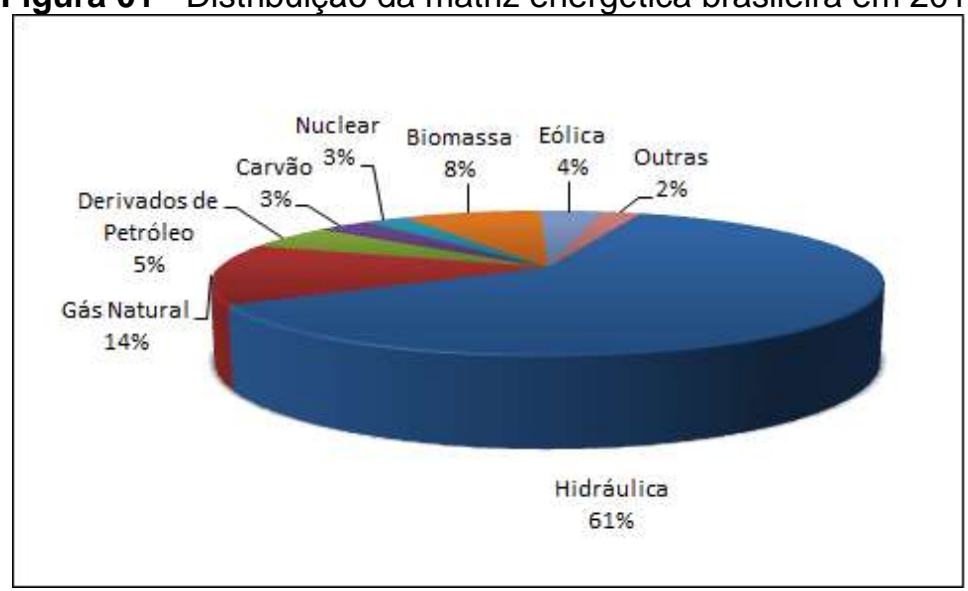

Fonte: EPE (2016)

Comparando a figura 01 com os índices de geração de energia elétrica em 2014 é possível perceber a queda no percentual de geração hidráulica, gás natural e nuclear, ocasionando um aumento de outras fontes de geração, como a biomassa e principalmente a eólica, que teve um aumento significativo de 1,7\% com relação ao ano anterior. Mesmo que pequenas tais alterações mostram que o cenário vem mudando no que diz respeito a investimentos em energia renovável (EPE, 2015).

A energia consumida está diretamente relacionada aos estágios do desenvolvimento antropológico, desde o homem primitivo ao tecnológico. Com a Revolução Industrial e consequente crescimento populacional dos grandes centros urbanos, teve início uma exploração desenfreada dos recursos naturais, onde o principal objetivo era a produção de energia em larga escala, buscando aumentar a capacidade de produção industrial e promover o crescimento urbano, produzindo cada vez mais, desconsiderando os impactos relativos. Essa ação antropológica encadeou uma série de problemas ambientais, os quais ameaçam a sobrevivência e bem-estar das gerações futuras (DUPONT, et al. 2015, GOLDEMBERG e LUCON, 2011).

Para Santos (2015), todas as fontes de geração de energia elétrica apresentam impacto ambiental associado, sendo que em alguns casos esse impacto é maior que em outros. A Tabela 02 apresenta um comparativo entre os pontos positivos e negativos quanto à utilização de cada fonte: 
Tabela 02 - Comparativo entre as fontes de energia

\begin{tabular}{|c|c|c|}
\hline Fontes de Energia & Pontos Positivos & Pontos Negativos \\
\hline Energia eólica & $\begin{array}{l}\text { Baixo impacto ambiental; } \\
\text { sem emissăo de } \\
\text { poluentes; fonte renovável. }\end{array}$ & $\begin{array}{l}\text { Poluição visual; } \\
\text { intermitência dos ventos. }\end{array}$ \\
\hline Energia Solar & $\begin{array}{l}\text { Baixo impacto ambiental; } \\
\text { sem emissăo de } \\
\text { poluentes; fonte renovável. }\end{array}$ & $\begin{array}{l}\text { Intermitência de luz solar; } \\
\text { baixa eficiência. }\end{array}$ \\
\hline Energia hidrica & $\begin{array}{l}\text { Sem emissăo de } \\
\text { poluentes; fonte renovável; } \\
\text { alta eficiência. }\end{array}$ & $\begin{array}{l}\text { Impacto ambiental devido } \\
\text { ao desvio de rios e } \\
\text { alagamentos de grandes } \\
\text { áreas. }\end{array}$ \\
\hline Energia fóssil & Facilidade de transporte. & $\begin{array}{l}\text { Alta emissão de poluentes } \\
\text { que causam chuva ácida; } \\
\text { emissão de gases estufa. }\end{array}$ \\
\hline Energia nuclear & $\begin{array}{l}\text { Năo emite gases do efeito } \\
\text { estufa. }\end{array}$ & $\begin{array}{l}\text { Lixo radioativo e perigo de } \\
\text { contaminação por } \\
\text { radiaçăo; poluição } \\
\text { térmica. }\end{array}$ \\
\hline Energia de biocombustive & $\begin{array}{l}\text { Fonte renovâvel; não emite } \\
\text { poluentes que causam } \\
\text { chuva ácida. }\end{array}$ & $\begin{array}{l}\text { Emissão de gases estufa; } \\
\text { competiçăo com a } \\
\text { produção de alimentos. }\end{array}$ \\
\hline Energia geotêrmica & $\begin{array}{l}\text { Sem emissão de } \\
\text { poluentes; }\end{array}$ & $\begin{array}{l}\text { Restrita a certas } \\
\text { localidades; }\end{array}$ \\
\hline Energia de marés & $\begin{array}{l}\text { Sem emissăo de } \\
\text { poluentes; fonte renovável. }\end{array}$ & $\begin{array}{l}\text { Restrita a certas } \\
\text { localidades; Impacto ao } \\
\text { ecossistema local. }\end{array}$ \\
\hline Energia de células & $\begin{array}{l}\text { Baixa emissăo de } \\
\text { poluentes em células a } \\
\text { combustivel. }\end{array}$ & $\begin{array}{l}\text { Residuos de metais } \\
\text { pesados em alguns tipos } \\
\text { de baterias. }\end{array}$ \\
\hline
\end{tabular}

Fonte: Creton e Sthel (2011)

Para Rocha (2016), é impossível retroceder do estágio tecnológico atual, onde a sociedade está consolidada no consumismo e exploração natural exacerbada. Isso provavelmente levará o planeta ao seu esgotamento, já que é sabido que não existem recursos energéticos suficientes para acompanhar o ritmo e intensidade dos processos de desenvolvimento.

No entanto, a sociedade tem voltado suas atenções para as consequências do impacto humano sobre o meio ambiente. O desperdício e uso desenfreado de recursos naturais e energéticos ameaçam a segurança, produtividade econômica, saúde e qualidade de vida das gerações atuais e futuras. Dessa forma, a questão ambiental passou a ser uma preocupação dos cidadãos, com interesse pelos recursos naturais esgotáveis e educação ambiental (REIS, 2005, CAMPOS; RAMOS; AZEVEDO, 2016).

Dentre as consequências atribuídas à geração e consumo excessivo de energia, estão a intensificação do efeito estufa antropogênico e o buraco na camada 
de ozônio, principalmente quando essa energia é proveniente de fontes não renováveis (BARBIERI, 2011).

O efeito estufa é um fenômeno fundamental para a manutenção da vida na Terra. Seus gases, dióxido de carbono $\left(\mathrm{CO}_{2}\right)$, ozônio $\left(\mathrm{O}_{3}\right)$, metano $\left(\mathrm{CH}_{4}\right)$, óxido nitroso $\left(\mathrm{N}_{2} \mathrm{O}\right)$, vapor d'água entre outros, funcionam como uma camada de proteção, permitindo que a radiação solar que chega até a Terra não seja totalmente irradiada de volta para o espaço, mantendo o equilíbrio do planeta e a superfície terrestre aquecida. Na ausência desse fenômeno natural, a Terra seria muito mais fria e segundo muitos pesquisadores, é a ação antropogênica que faz com que haja o aumento excessivo dos gases do efeito estufa, de modo a interferir na temperatura global (SILVA E PAULA, 2009).

O aquecimento global está diretamente relacionado ao aumento da concentração desses gases, uma vez que sua concentração excessiva na atmosfera impede que a radiação solar seja emitida de volta ao espaço, esta acaba ficando retida na superfície, o que provoca o aumento da temperatura média global. $\mathrm{O}$ aumento da temperatura, por sua vez, encadeia uma série de problemas ambientais, como a mudança nos ciclos de chuvas e circulação de ar, grandes períodos de estiagem, maior incidência de maremotos e furacões, elevação do nível dos oceanos, proveniente do derretimento das calotas polares e alterações sistemáticas dos ecossistemas (BARBIERI, 2011).

O buraco na camada de ozônio, essa constituída por um conjunto de moléculas de Ozônio $\left(\mathrm{O}_{3}\right)$, sendo responsável pela absorção de $95 \%$ da radiação ultravioleta nociva, impedindo-a de atingir a Terra, também é um problema que requer atenção. A existência dessa camada garante a vida de organismos unicelulares e de células superficiais de plantas e animais, além de impedir eventuais danos ao material genético humano, o que potencialmente provocaria o câncer. Os clorofluorcarbonos (CFC's) utilizados em larga escala na indústria, quando lançados à atmosfera rompem-se sob influência da radiação ultravioleta, liberando átomos altamente reativos. A consequência dessa ação antropogênica é a destruição das moléculas de ozônio, que são quebradas mais rapidamente do que se formam, expondo os seres vivos à radiação (CRETON; STHEL, 2011).

Algumas linhas de pesquisa atribuem o aquecimento do planeta ao final da atual era glacial, afirmando que este não tem relação com a interferência 
antropogênica no meio ambiente. As eras glaciais são caracterizadas pela presença de gelo, ocasionando temperaturas mais amenas e clima frio. Já as interglaciais, ocorre a total ausência de gelo sobre a superfície da Terra, e o clima esquenta devido às temperaturas elevadas. Para alguns estudiosos, o planeta Terra estaria passando pela transição da era glacial para a interglacial, o que estaria de fato causando o aumento da temperatura global (SILVA; PAULA, 2009).

Fato é que desde o início da Era Industrial, as concentrações de gases intensificadores do efeito estufa têm aumentado largamente devido as emissões antropogênicas para $\mathrm{CO}_{2}, \mathrm{CH}_{4}$ e $\mathrm{N}_{2} \mathrm{O}$, como mostra a Tabela 3:

\begin{tabular}{|c|c|c|}
\hline $\begin{array}{c}\text { GASES DO } \\
\text { EFEITO ESTUFA }\end{array}$ & $\Delta \mathrm{T}$ & CRESCIMENTO \\
\hline Vapor D’água & $20^{\circ} \mathrm{C}$ & - \\
\hline $\begin{array}{c}\text { Dióxido De } \\
\text { Carbono }\end{array}$ & $7^{\circ} \mathrm{C}$ & $36 \%$ \\
\hline Ozônio & $2 \mathrm{~A} 3^{\circ} \mathrm{C}$ & - \\
\hline $\begin{array}{c}\text { Óxido Nitroso ( } \mathrm{N}_{2} \mathrm{O}, \\
\text { Derivados) }\end{array}$ & $1,4^{\circ} \mathrm{C}$ & $18 \%$ \\
\hline Metano & $0,8^{\circ} \mathrm{C}$ & $150 \%$ \\
\hline Demais Gases & $0,6^{\circ} \mathrm{c}$ & - \\
\hline
\end{tabular}

Fonte: Nobre, Reid e Veiga (2012)

A Tabela 3 representa a influência dos gases do efeito estufa no aumento de temperatura. $\mathrm{O} \mathrm{CO}_{2}$, considerado o principal agente do aquecimento global, influencia em $7^{\circ} \mathrm{C}$ na temperatura se considerar o efeito estufa natural. No entanto, a concentração desse gás aumentou $36 \%$ desde os primórdios da Revolução Industrial. Isso mostra que de certo modo, a temperatura certamente é influenciada pelo aumento na concentração tanto do $\mathrm{CO}_{2}$, quanto de outros gases (CRETON; STHEL, 2011).

De acordo com Oliveira et al (2015), o setor industrial tem influenciado negativamente ao ambiental em nível global, sendo responsável por grande parcela dos gases do efeito estufa lançados na atmosfera, assim como por enorme parcela da água e energia consumidas no planeta. Apesar do impacto ambiental, é essencial considerar a forte influência desse setor na economia e no desenvolvimento do país, já que o setor responde por $22,7 \%$ do Produto Interno Bruto- PIB e a $23,6 \%$ da massa 
salarial brasileira (CNI, 2016).

Em 2015, o setor industrial viu seus custos de produção aumentarem 8,1\%. O custo com energia elétrica foi o principal responsável por esse aumento, sofrendo um ajuste de 38,9\% com relação ao ano de 2014 e apresentando um crescimento efetivo de $51,1 \%(\mathrm{CNI}, 2016)$.

Diante do cenário atual de mudança de hábitos e mercado competitivo, as organizações têm visto a gestão ambiental como uma oportunidade para melhorar e controlar suas atividades. É crucial o desenvolvimento de modelos de gestão de recursos naturais e energéticos que contribuam simultaneamente para a criação de valor de longo prazo e para a solução dos problemas ambientais e sociais. Dessa forma, os negócios sustentáveis ganham cada vez mais espaço e são caracterizados como aqueles que utilizam os recursos de forma sustentável para atender suas necessidades, desenvolvendo tecnologias limpas, renovação de recursos, reciclagem de materiais e arcando com impactos sociais e ambientais provenientes de seus processos produtivos (BARBIERI, 2011; TRIERWEILLER et. al, 2014).

Nesse contexto, a gestão energética surge como estratégia das organizações para curto, médio e longo prazo. A política energética corporativa tem por objetivo a análise de eventuais situações de desabastecimento causadas pelo desequilíbrio entre oferta e demanda, assim como aspectos legais e regulatórios dos mercados de energia, avaliação dos impactos ambientais atrelados ao consumo de energia na cadeia produtiva e desenvolvimento de alternativas "limpas" e sustentáveis de geração. Deste modo, é de fundamental importância desenvolver métodos para aperfeiçoar o desempenho energético no campo industrial, assim como minimizar as perdas de energia dos processos produtivos (MARQUES, 2007).

Para Baumgartner (2008) e Rodrigues (2015), avaliar o desempenho sustentável das organizações é um passo importante para a sociedade moderna. Essa avaliação ocorre por meio de três estágios de impacto: grau de contribuição para aumento de emissões de substâncias nocivas ao meio ambiente, degradação da natureza por meio da superexploração e uso ineficiente dos recursos naturais. Os parâmetros de avaliação devem ainda ser sistêmicos, analisados para diversos contextos, como gestão organizacional, recursos humanos, produto, processo produtivo, instalações físicas, emissões, desenvolvimento social, aspecto econômico financeiro e marketing. 
Segundo May (2010), o principal obstáculo à introdução de ações sustentáveis na empresa é a falsa noção de que meio ambiente e lucro são adversários naturais, o que é um grande equívoco. Pelo contrário, a adoção de práticas sustentáveis implica na racionalização dos recursos naturais e insumos do processo produtivo, o que reduz consideravelmente os custos de produção, elevando a competitividade da organização.

Devido às políticas de gestão ambiental e energética possuírem inércia de médio e longo prazo, isso acaba desencorajando muitas indústrias que buscam resultados imediatos como forma de aumentar a competitividade. No entanto, um estudo de viabilidade ao início do projeto é capaz de prever, com o auxílio de indicadores econômicos, a rentabilidade das ações de EE- Eficiência Energética, assim como os impactos futuros no ambiente organizacional. O payback, por exemplo, é um indicador econômico que permite identificar o prazo ao qual é possível recuperar o investimento, momento no qual o lucro do projeto é igual ao investimento realizado (MAY, 2010; TORRES, 2000).

Em estudo realizado por Artiach et al (2010), procurou-se medir os fatores que influenciam os altos índices de desempenho de algumas organizações quanto ao desempenho vinculado à sustentabilidade empresarial. Os resultados indicaram que empresas líderes em investimentos e práticas sustentáveis aproveitam ao máximo os incentivos do governo e apresentam níveis mais altos de crescimento e retorno sobre o patrimônio líquido do que as empresas convencionais.

Diversos modelos de gestão sustentável já são discutidos e aplicados em muitas corporações, entre eles a Ecoeficiência. Trata-se de um modelo de gestão empresarial em que se industrializa de forma a satisfazer as necessidades humanas e melhorar a qualidade de vida, ao mesmo tempo que reduz progressivamente os impactos ecológicos e a intensidade dos recursos ao longo do seu ciclo de vida, mantendo o equilíbrio energético do planeta. As práticas ecoeficientes consistem em minimizar a quantidade disponibilizada de produtos e serviços e a quantidade de energia necessária à fabricação, assim como aumentar o grau de reciclagem e durabilidade dos produtos, elevando o uso sustentável dos recursos renováveis (BARBIERI, 2011).

Já o modelo de gestão voltado para a economia e uso eficiente de energia denomina-se eficiência energética. Salum (2005) afirma que "eficiência energética é 
utilizar a energia de forma a obter o máximo benefício com o menor consumo, evitando os desperdícios ou o uso inadequado, sem diminuir a qualidade de vida ou produtividade".

No entanto, apenas gerir o recurso não é o suficiente. Muito pouco tem sido feito em nível prático quanto à adoção de estratégias mais sustentáveis. É necessário que os gestores adotem práticas sustentáveis, mesmo que pontuais, visto que ignorálas pode agravar o problema e culminar na indisponibilidade dos recursos naturais. Deste modo, o uso de fontes alternativas de geração de energia surge como uma alternativa capaz de unir interesses econômicos e ambientais, já que a energia representa um custo substancial em qualquer processo produtivo (AZAPAGIC; PERDAN, 2000).

Documentos divulgados pelo Centro de Gestão e Estudos Estratégicos- CGEE em 2010, órgão vinculado ao Ministério de Ciência, Tecnologia e Inovação, estimam que em 2050, 50\% da geração de energia no mundo será proveniente de fontes renováveis. Dessa demanda, $25 \%$ será suprida pela energia solar fotovoltaica. A expectativa é de que até o final do século XXI a população dependerá em até $90 \%$ das fontes renováveis, sendo $70 \%$ dessa demanda suprida pela energia solar fotovoltaica.

A tecnologia fotovoltaica - TF é a que mais tem se destacado nos debates atuais acerca de energias renováveis. $\mathrm{O}$ sol fornece anualmente para a atmosfera terrestre $1,5 \times 1018 \mathrm{kWh}$ de energia, o que corresponde a dez mil vezes o consumo mundial de energia elétrica. Dessa forma, a radiação solar constitui uma inesgotável fonte de energia, com grande potencial de utilização. Uma das possíveis formas de conversão consiste nas células fotovoltaicas, componentes optoeletrônicos que convertem diretamente a radiação solar em eletricidade, conforme apresentado na Figura 02 (CRESESB, 2017). 
Figura 02 - Esquema de funcionamento da tecnologia fotovoltaica

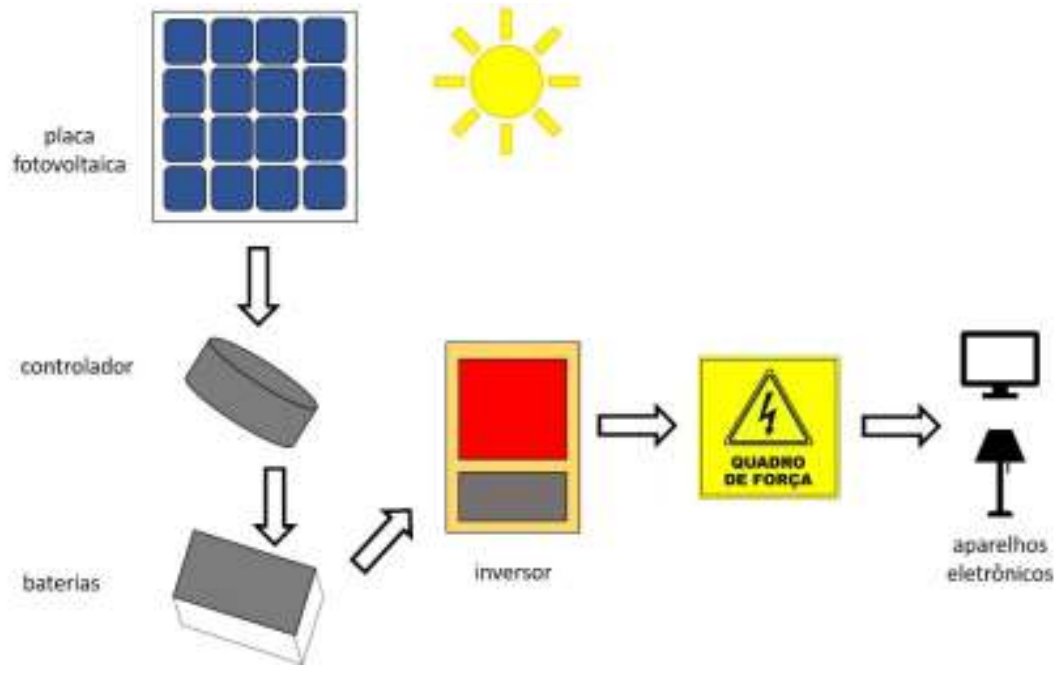

Fonte: Elaborado pelos autores

A Figura 3 permite perceber que a capacidade instalada mundial da geração fotovoltaica cresceu 98\% de 2004 a 2014, sendo 43,5\% em apenas três anos, alcançando a capacidade instalada de 177 GW de potência em 2014.

Figura 03 - Capacidade mundial instalada da TF em 2014

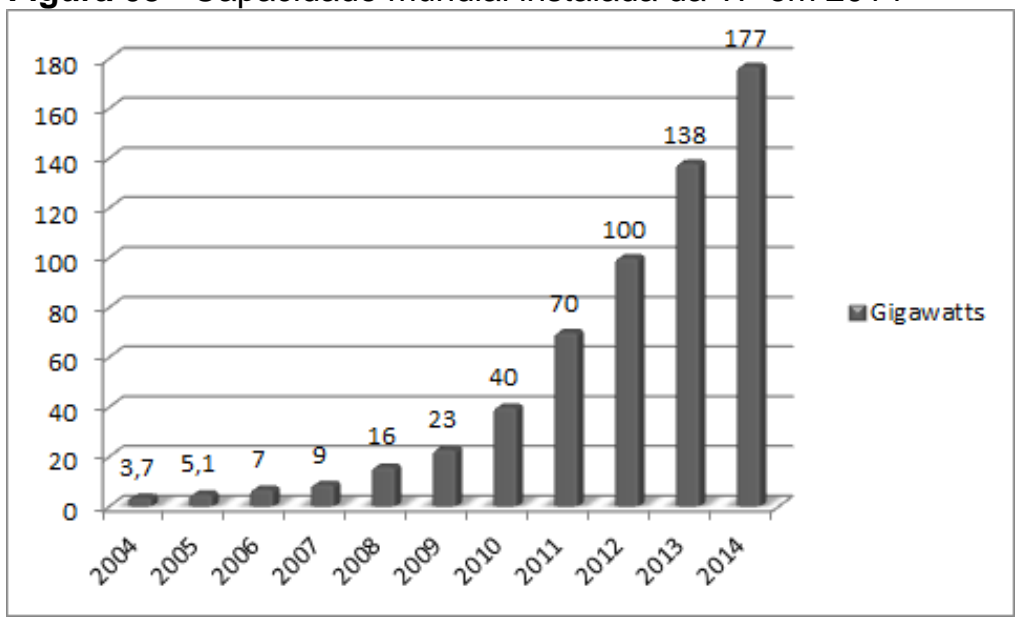

Fonte: REN21 (2015)

Os painéis fotovoltaicos captam a luz solar e transformam a radiação em eletricidade. Esses painéis também podem ser conectados à rede elétrica, transformando a energia solar em corrente contínua, gerando energia elétrica que se iguala a produzida pelas concessionárias. O Brasil possui uma média anual de radiação global entre 1.642 e $2300 \mathrm{KWh} / \mathrm{m}^{2} /$ ano e apenas 5\% dessa energia atenderia toda a demanda brasileira por eletricidade (GREENPEACE, 2010).

Ainda segundo o Greenpeace (2010), as vendas de painéis fotovoltaicos Revista Produção Online. Florianópolis, SC, v. 18, n. 1, p. 238-264, 2018. 
cresceram 30\% nos períodos de 2005 a 2010, e as células tiveram uma queda de preço de aproximadamente $20 \%$ no mesmo período. A expectativa é que num futuro próximo estas se tornem competitivas em relação ao preço médio das tarifas elétricas praticadas, sendo adotadas por uma parcela maior da população.

Os cálculos de quantidade de energia gerada pelo sistema fotovoltaico são realizados por meio do monitoramento da densidade das nuvens e da variação do grau de irradiação solar durante o período em que se pretende avaliar. A eficiência do sistema gira em torno de $25 \%$, e é medida em termos da quantidade de radiação solar incidente sobre as placas que é convertida em energia elétrica. No entanto, maiores índices de eficiência podem ser conseguidos de acordo com o material utilizado como matéria prima das placas fotovoltaicas (ALDABÓ, 2002).

Vários países têm desenvolvido ações de políticas energéticas tentando adequar-se às novas tendências e necessidades socioambientais. $E$ sobre essa temática, o Brasil atua principalmente através da Agência Nacional de Energia Elétrica - ANEEL.

\section{METODOLOGIA}

Com o intuito de atender aos objetivos propostos neste estudo, a metodologia utilizada baseou-se em uma série de etapas, as quais é possível listar: levantamento bibliográfico, utilizado para a construção de uma base teórica capaz de proporcionar respostas às questões problema levantadas; coleta de dados, por meio de entrevistas semiestruturadas e visitas às instalações da empresa, as quais proporcionaram a observação direta das atividades e da rotina organizacional; desenvolvimento de modelo de gestão capaz de alinhar interesses econômicos e socioambientais; análise de viabilidade econômica da proposta levantada, por meio do tratamento dos dados coletados.

Esta pesquisa partiu de uma abordagem quali-quantitativa, a qual permite ao pesquisador a realização de cruzamentos de suas conclusões de modo a obter mais confiança de que os dados coletados são de fato satisfatórios, testando a hipótese levantada. Segundo Minayo (1993), a relação entre qualitativo e quantitativo não pode ser pensada como oposição, de modo a permitir que os objetos de estudo possam ser analisados em seus aspectos mais concretos e aprofundados em seus significados mais essenciais. Dessa forma, o estudo qualitativo pode gerar questões para serem 
aprofundadas quantitativamente, e vice-versa.

Quanto ao método de pesquisa, este estudo pode ser caracterizado como um estudo de caso por representar uma estratégia de pesquisa que utiliza métodos que abrangem a coleta e a análise de dados, em busca da identificação, análise e interpretação dos fenômenos observados nas organizações (YIN, 2001, MIGUEL, 2012).

Para a coleta de dados foram utilizados dois questionários, ambos aplicados ao gerente geral da organização estudada. As observações e entrevistas foram conduzidas dentro da organização, entre os meses de junho de 2015 e março de 2016.

O primeiro questionário teve por objetivo identificar os fatores relacionados ao consumo de energia pelo setor de tecelagem da organização, tais como potenciais consumidores, média de consumo e a problemática enfrentada pela mesma no que tange à gestão energética. Num segundo momento, conhecida a problemática, objetivou-se compreender a cultura organizacional quanto às questões ambientais e energéticas, além de adotar uma abordagem mais técnica, coletando dados quantitativos necessários à realização de um estudo de viabilidade para embasamento da proposta.

Houve grande dificuldade durante a etapa de coleta de dados quantitativos, onde a organização mostrou-se receosa em fornecer informações concretas a respeito do consumo real de energia em $\mathrm{kW}$, assim como outros aspectos relacionados à valores monetários e políticas ambientais já estabelecidas. Deste modo, muitas análises foram realizadas com base em estimativas, baseadas nas informações conseguidas nos questionários.

Buscando realizar uma análise robusta a respeito da viabilidade da instalação de uma usina fotovoltaica nas dependências da fábrica, foi contatado um profissional da área de Engenharia Elétrica com ênfase em eletroeletrônica, o qual possui experiência em cálculos de potência de sistemas fotovoltaicas. Este forneceu e indicou as referências técnicas e os parâmetros utilizados no cálculo da potência do sistema.

Os dados estimados foram tabulados no software Microsoft Excel 2010, onde também foram plotados os gráficos de viabilidade econômica do investimento. 


\subsection{A Empresa Mineira do Setor Têxtil}

O setor industrial têxtil mostra-se de grande relevância no cenário econômico e social brasileiro. De acordo com relatório divulgado pela empresa Inteligência de Mercado - IEMI (2016), a cadeia têxtil produziu 126 bilhões e empregou 16,9\% do total de trabalhadores da classe industrial em 2014. Apesar disso, o principal desafio do setor para os próximos anos é a elevação dos custos de produção, com o aumento dos valores da água e energia fornecidas pelas empresas tradicionais de abastecimento e distribuição.

A fábrica têxtil em questão, denominada no presente trabalho como Empresa Beta (nome adotado pelos autores a fim de preservar informações estratégicas da organização, a pedido da mesma), atua há 130 anos no mercado e produz artigos têxteis para a linha lar.

A Empresa Beta é uma organização verticalmente integrada, atuando em praticamente todos os elos da cadeia têxtil, englobando os setores de beneficiamento de algodão, fiação, tecelagem, acabamento e confecção. Dispõe ainda de lojas próprias para comercialização dos seus produtos.

Identificando a energia como um insumo essencial para a manutenção do negócio, a empresa construiu duas usinas hidrelétricas, que por muitos anos atenderam à demanda energética da indústria, fazendo com que essa utilizasse uma cota mínima da Companhia Energética de Minas Gerais- CEMIG. No entanto, devido às recentes alterações climáticas e ao período de seca enfrentado pelo Brasil principalmente nos anos de 2014 e 2015, as usinas ficaram inoperantes. Os custos com energia eram em torno de 150 mil reais mensais antes da crise climática e após essa até a data da finalização da pesquisa, ultrapassam meio milhão de reais.

O aumento dos custos impactou no preço praticado no mercado, interferindo na competitividade da organização. Como alternativa para minimizar o problema, decidiu-se por parar alguns setores de produção nos horários de pico, o que culminou em recursos ociosos e perda da produtividade, além do surgimento de sérios problemas de planejamento e controle da produção.

O problema enfrentado pela Empresa Beta remete à dependência da matriz energética brasileira quanto à geração de energia por usinas hidroelétricas. Nos períodos de seca, os impactos são rapidamente percebidos. 
Considerando o contexto cultural da organização, foi elaborado um plano de eficiência energética baseado no Triple Bottom Line, ou Tripé da Sustentabilidade, buscando equilibrar os aspectos economicamente viáveis, ambientalmente corretos e socialmente responsáveis, não permitindo a priorização de um aspecto ou outro (SILVA, 2015).

Por meio da aplicação dos questionários, foi possível identificar o perfil ambiental da organização, assim como o grau de interesse em investimentos em novas tecnologias para geração de energia. A Figura 04 apresenta em síntese o mapeamento dos interesses e práticas ambientais da organização, assim como informações técnicas relacionadas ao consumo de energia na fábrica.

No que tange o pilar econômico, que remete à redução imediata no consumo de energia, foi possível mapear o processo produtivo de modo a conhecer os setores ou equipamentos com maior consumo, sendo eles climatização, tecelagem e fiação. A fim de atuar corretivamente nos potenciais consumidores, foi elaborado um modelo 5W1H para acompanhamento e aplicação dos indicadores de eficiência energética, neste caso, para o exemplo hipotético do setor de tecelagem. O modelo é apresentado na Tabela 04.

A sugestão é analisar simultaneamente os indicadores apresentados na Tabela 04 e identificar potenciais desperdícios nos processos/equipamentos, de modo a calcular a demanda por energia para a fabricação de um determinado produto e o consumo real do equipamento. A partir dos indicadores é possível conhecer a contribuição da energia no custo do produto, o que pode interferir diretamente no preço praticado e na competitividade da empresa perante o mercado, sendo possível analisar quanto se fatura com cada $\mathrm{kW}$ consumido e efetivamente, verificar o quanto de energia foi economizada, resultado das ações de eficiência implantadas.

Ainda considerando o critério econômico, foi analisada a proposta de instalação de uma usina fotovoltaica nas dependências da fábrica, de modo a atender sua demanda energética, reduzindo seus custos com o insumo.

Importante mencionar que por questões estratégicas, a organização optou por não detalhar o consumo mensal exato de energia elétrica $\mathrm{em} \mathrm{kw} / \mathrm{h}$, tampouco forneceu o histórico de consumo da indústria. Portanto, o valor apresentado na Figura 04 faz referência à média de consumo informada pelos gestores da indústria no momento da entrevista. A fim de traduzir o gasto total com energia em $(\mathrm{kw} / \mathrm{h})$, foram considerados 
os encargos e tributos aplicados pela CEMIG e pelo município onde a indústria está localizada.

Figura 04 - Perfil ambiental da organização

\begin{tabular}{|ll|}
\hline Práticas Ambientais & $\begin{array}{l}\text { Tratamento e recuperação de efluentes } \\
\text { Filtros nas chaminés para retenção de gases } \\
\text { Reflorestamento } \\
\text { Reciclagem de residuos provenientes do processo produtivo }\end{array}$ \\
\hline Fonte de energia utilizada & Energia elétrica proveniente da geração hidráulica \\
\hline Fonte de abastecimento & CEMIG- Companhia Energética de Minas Gerais \\
\hline $\begin{array}{ll}\text { Custo com energia elétrica (média dos últimos } \\
12 \text { meses) }\end{array}$ & $\mathrm{R} \$ 500.000$ \\
\hline Consumo em Kw/h/mês & 471019 \\
\hline $\begin{array}{l}\text { Interesse em fontes alternativas (As fontes } \\
\text { aparecem na sequência em que foram citadas }\end{array}$ & \\
pelo entrevistado) & Sim: Energia eólica, Energia Solar, Biomasssa \\
\hline \hline
\end{tabular}

Fonte: Elaborado pelos autores

Tabela 04 - Modelo 5W1H de indicadores de eficiência energética para o setor de tecelagem

\begin{tabular}{|c|c|c|c|c|c|}
\hline O quê- Indicador & Quando? & Onde? & Por que? & Quem? & Como? \\
\hline Demanda Específica & 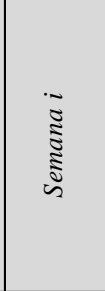 & $\sqrt{\overline{3}}$ & $\begin{array}{l}\text { Determinar a demandas de energia } \\
\text { em kWh para cada tipo de tecido do } \\
\text { portifólio, levando em conta o } \\
\text { volume de produção demandado de } \\
\text { cada item. }\end{array}$ & 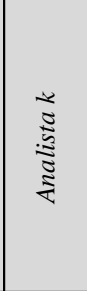 & $\begin{array}{l}\text { De }=\text { Dme/Pe } \\
\text { Onde: } \\
\text { Dme: Demanda média da energia } \\
\text { elétrica na produção = Energia } \\
\text { consumida/1 hora } \\
\text { Pe: Produção específica de um item } \\
\text { durante } 1 \text { hora em unidades, } \\
\text { toneladas, litros, etc. }\end{array}$ \\
\hline Consumo Específico & 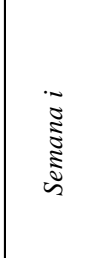 & $\sqrt{\overline{3}}$ & $\begin{array}{l}\text { Monitorar a utilização de energia e o } \\
\text { desempenho do tear e determinar a } \\
\text { real economia de energia, pela } \\
\text { análise de sua evolução. }\end{array}$ & 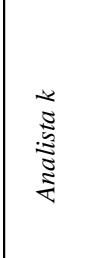 & $\begin{array}{l}\mathbf{C e}=\mathbf{E e c} \text { / Pe } \\
\text { Onde: } \\
\text { Eec: energia elétrica consumida na } \\
\text { produção (excluída energia utilizada } \\
\text { para fins administrativos); } \\
\text { Pe: produção específica em } \\
\text { unidades, toneladas, litros, etc. }\end{array}$ \\
\hline $\begin{array}{l}\text { Participação da energia no } \\
\text { custo do produto }\end{array}$ & 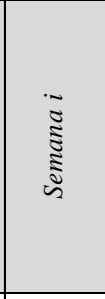 & $\sqrt{\overline{3}}$ & $\begin{array}{l}\text { Medir a contribuição percentual da } \\
\text { energia no custo da produção. }\end{array}$ & 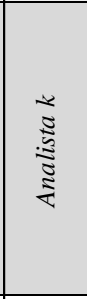 & $\begin{array}{l}\text { Pec= \$MWh / C\$ } \\
\text { Onde: } \\
\text { Pec: participação da energia no } \\
\text { custo do produto } \\
\text { \$MWh: preço da energia elétrica, } \\
\text { em reais; } \\
\text { C\$: custo da produção específica, } \\
\text { em reais. }\end{array}$ \\
\hline $\begin{array}{c}\text { Valor Agregado da energia } \\
\text { elétrica }\end{array}$ & 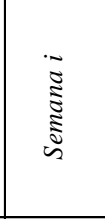 & 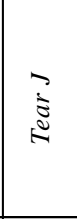 & $\begin{array}{l}\text { Calcular quanto se fatura com um } \\
\text { kWh consumido, e } \\
\text { consequentemente, quanto se ganha } \\
\text { com um kWh economizado. }\end{array}$ & 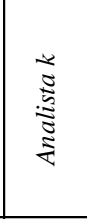 & $\begin{array}{l}\text { Vae }=\text { V\$ / MWh } \\
\text { Onde: } \\
\text { V\$: valor da produção específica, } \\
\text { em reais; } \\
\text { MWh: consumo da energia elétrica } \\
\text { específica (em MWh) }\end{array}$ \\
\hline $\begin{array}{l}\text { Energia Elétrica } \\
\text { Economizada }\end{array}$ & $\begin{array}{l}\tilde{z} \\
\tilde{\Xi} \\
\vdots \\
\tilde{\Xi} \\
\tilde{\omega}\end{array}$ & $\overline{3}$ & $\begin{array}{c}\text { Identificar os resultados de } \\
\text { economia de energia em } \mathrm{kW} \text {, } \\
\text { consequência das ações preventivas } \\
\text { e corretivas aplicadas. Este } \\
\text { indicador é calculado com o auxílio } \\
\text { do indicador de Consumo } \\
\text { Específico. }\end{array}$ & 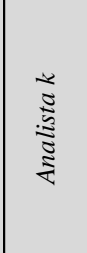 & $\begin{array}{l}\mathbf{E e e}=\left[\left(\mathbf{C e}_{\mathbf{a}}-\mathbf{C e}_{\mathbf{p}}\right) / \mathbf{C e}_{\mathbf{a}}\right] \mathbf{x} \mathbf{E e c} \\
\text { Onde: } \\
\text { Cea: consumo específico anterior; } \\
\text { Cep: consumo específico posterior; } \\
\text { Eec: energia elétrica consumida na } \\
\text { produção (em kWh). }\end{array}$ \\
\hline
\end{tabular}

Fonte: Adaptado de SALUM (2005)

Revista Produção Online. Florianópolis, SC, v. 18, n. 1, p. 238-264, 2018. 
A Figura 05 apresenta os tributos aplicáveis à conta de energia: Imposto Comercial sobre Mercadorias e Serviços - ICMS, Contribuição para o Financiamento da Seguridade Social- Confins, Programa de Formação de Patrimônio do Servidor Público- Pasep e Custeio para o Serviço de lluminação Pública- CIP, cujo percentual fica a cargo de cada município instituir.

Figura 05 - Encargos e Tributos

\begin{tabular}{|lrr|}
\hline Média de gastos mensais com energia elétrica da & & \\
indústria & $\mathrm{R} \$$ & $500.000,00$ \\
(-) ICMS- 18\% (ANEEL,2016) & $-\mathrm{R} \$$ & $90.000,00$ \\
(-) COFINS- 7,6\% (CEMIG,2016) & $-\mathrm{R} \$$ & $38.000,00$ \\
(-) PASEP- 1,18\% (CEMIG, 2016) & $-\mathrm{R} \$$ & $5.900,00$ \\
(-) CIP- 10\% (P.M.Alvinópolis, 2015) & $-\mathrm{R} \$$ & $50.000,00$ \\
(=) Gasto com kw/h & RS & $\mathbf{3 1 6 . 1 0 0 , 0 0}$ \\
\hline
\end{tabular}

Fonte: Elaborado pelos autores

Faz-se necessária uma segunda análise a respeito do consumo/custo da energia, já que a indústria opera em regime integral, e a energia elétrica chega a custar 3,76 vezes mais em horários de pico, no estado de Minas Gerais. A Figura 06 apresenta a base de cálculo, considerando horários de pico e fora de pico, para o período de um mês, o que permitiu estimar o consumo médio em $\mathrm{kw} / \mathrm{h}$ da indústria.

Figura 06 - Consumo final de energia em $\mathrm{kw} / \mathrm{h}$

\begin{tabular}{|lrr|}
\hline Gasto total com energia (em kw/h) & RS & $316.100,00$ \\
Horas totais de operação/mês & & $100 \%$ \\
Operação em HFP- Horário fora de pico & & $87,5 \%$ \\
Operação em HP- Horário de pico & & $12,5 \%$ \\
Gastos em HFP & RS & $167.533,00$ \\
Gastos em HP & RS & $148.567,00$ \\
Consumo HFP & RS & $389.611,63$ \\
Consumo HP & & 91708,02 \\
Consumo total (em kw/h) & & $\mathbf{4 8 1 3 1 9 , 6 5}$ \\
\hline
\end{tabular}

Fonte: Elaborado pelos autores

Diante da problemática apresentada e do interesse demonstrado pela indústria em investir em alternativas sustentáveis de geração de energia, foi realizada uma análise do perfil eólico e de radiação solar da cidade onde a empresa está localizada, a fim de conhecer qual alternativa ambientalmente correta que melhor se enquadra às 
necessidades da fábrica.

A partir dos dados coletados, foi possível verificar que a cidade na qual a fábrica está localizada apresenta bons índices de radiação solar durante o ano todo, como pode ser observado na Figura 07. Isso fez da energia solar fotovoltaica uma primeira opção de análise, sendo sugerida a instalação de um sistema de geração fotovoltaica autônomo.

Figura 07- Irradiação solar média na cidade da empresa Beta

\begin{tabular}{|c|c|c|c|}
\hline $\begin{array}{l}\text { Irradiação solar diária média } \\
\text { mensal }\left[\mathrm{kWh} / \mathrm{m}^{2} \cdot \text { dia] }\right.\end{array}$ & Inclinação $0^{\circ} \mathrm{N}$ & Inclinação $20^{\circ} \mathrm{N}$ & $\begin{array}{c}\text { Inclinação } 19^{\circ} \mathrm{N} \text { (Maior } \\
\text { média anual) }\end{array}$ \\
\hline Jan & 5,28 & 4,83 & 4,86 \\
\hline Fev & 5,25 & 5,02 & 5,04 \\
\hline Mar & 4,78 & 4,87 & 4,87 \\
\hline Abr & 4,11 & 4,51 & 4,5 \\
\hline Mai & 3,69 & 4,37 & 4,34 \\
\hline Jun & 3,47 & 4,28 & 4,25 \\
\hline Jul & 3,89 & 4,76 & 4,73 \\
\hline Ago & 4,44 & 5,09 & 5,07 \\
\hline Set & 4,11 & 4,29 & 4,29 \\
\hline Out & 4,67 & 4,56 & 4,57 \\
\hline Nov & 4,56 & 4,24 & 4,27 \\
\hline Dez & 4,86 & 4,42 & 4,45 \\
\hline
\end{tabular}

Fonte: Elaborado pelos autores

É sabido que a inclinação com que as placas fotovoltaicas são instaladas interfere na incidência da radiação solar sob a superfície dessas. Sabe-se ainda que a geração de energia dessas placas é diretamente proporcional à quantidade de radiação eminente sobre elas. Considerando que o sol nasce ao leste, sobe se inclinando ao norte e se põe ao oeste, um ângulo de inclinação igual ao da latitude é normalmente o melhor ângulo para se instalar um painel fotovoltaico. No Brasil, devido à posição privilegiada em relação ao sol, o ideal é que o sistema fotovoltaico tenha um grau de inclinação menor que o da latitude. Portanto, para a localidade analisada, o melhor ângulo de incidência é o de $19^{\circ} \mathrm{N}$, considerando uma latitude de $20^{\circ}$ (CRESESB, 2017). Estes índices serão utilizados para cálculo de potência mais adiante.

Considerando os índices de irradiação solar apresentados na Figura 07 e uma estimativa de consumo da fábrica em torno de $481.320 \mathrm{kw} / \mathrm{h} / \mathrm{mês}$, foi possível calcular a previsão de geração de energia da usina fotovoltaica, mês a mês, por meio de índices previamente estabelecidos pelo CRESESB (2017). Conforme dados do CRESCESB (2017), a geração de energia do período pôde então ser definida pela 
seguinte equação:

$$
\text { Geração de energia }=R p * D * N * \eta P V
$$

Onde:

$\mathrm{R}_{\mathrm{p}}=$ irradiação solar do período;

$D=$ Dimensão da placa fotovoltaica, geralmente comercializada com 1,63m;

$\mathrm{N}$ = número de placas fotovoltaicas, de acordo com a demanda de energia;

$\eta \mathrm{PV}=$ tensão de máxima potência da célula fotovoltaica.

A Figura 08 apresenta a quantidade de energia a ser gerada pela usina fotovoltaica para o período de um ano.

Figura 08 - Geração de energia da usina fotovoltaica

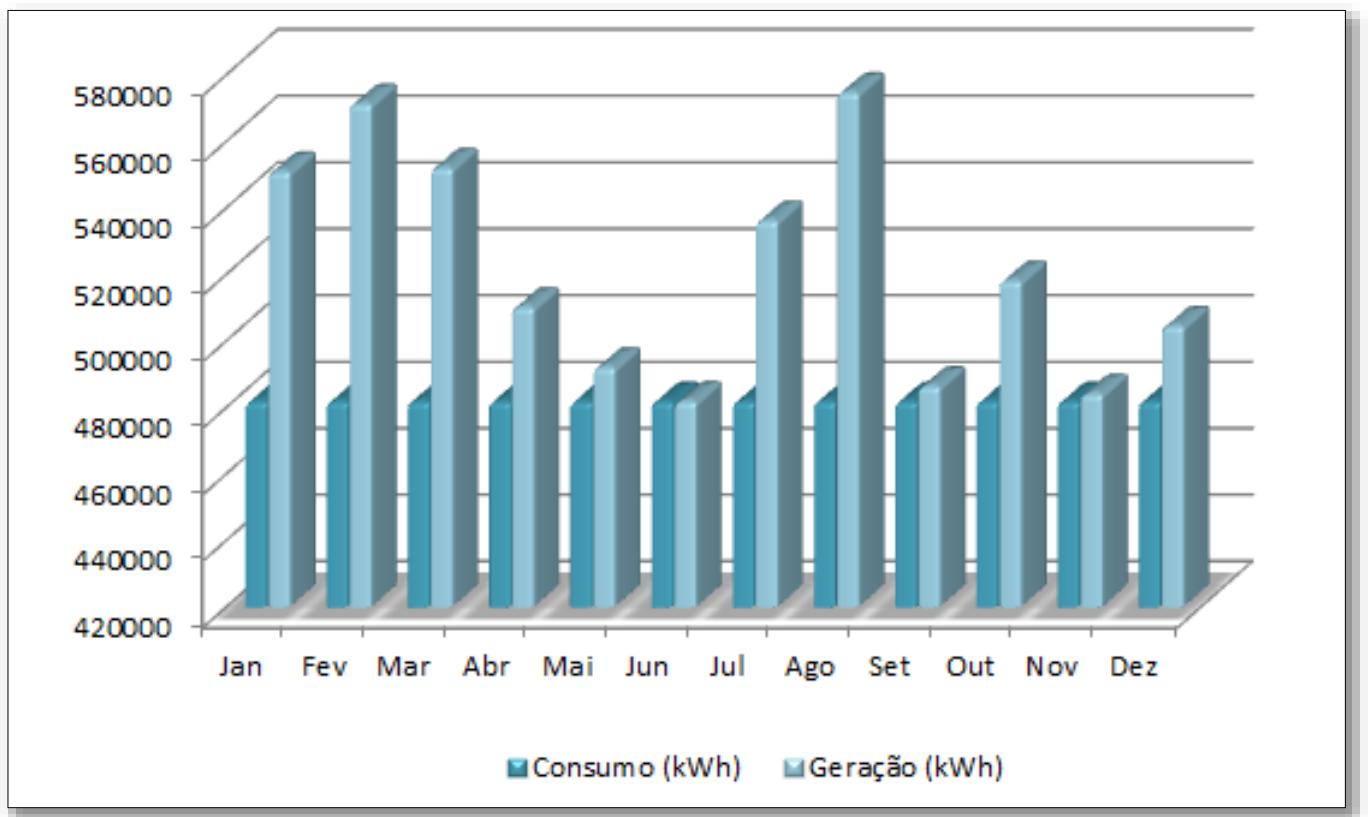

Fonte: Elaborado pelos autores

A Figura 08 permite considerar que diante da irradiação solar identificada, a demanda de energia da fábrica seria suprida durante todo o ano, e inclusive, em alguns períodos haveria geração superior à demanda, o que permitiria à empresa negociar a venda dessa energia para a concessionária de energia elétrica, por meio de um sistema interligado à rede. Para tal, todo o arranjo seria interligado a inversores, os quais seriam ligados diretamente à rede. 
Considerando a dimensão e a potência de geração das placas, os quais foram representados na Equação 01, seriam necessárias 13.955 placas fotovoltaicas para alcançar os índices de geração representados na Figura 08. Dessa forma, toda a demanda da fábrica seria suprida pela energia solar fotovoltaica, em todos os meses do ano.

Sempre quando se fala em geração de energia, logo se pensa em dispender grandes áreas territoriais para alocação de usinas. No entanto, uma característica favorável das usinas fotovoltaicas é que as placas podem ser alocadas nos telhados de áreas já construídas, o que reduz consideravelmente o capital investido. No caso da fábrica têxtil, a empresa possui cerca de $17.000 \mathrm{~m}^{2}$ de área construída, distribuídos entre galpões de produção e estoque, além de uma área livre ao redor da fábrica correspondente a $19.000 \mathrm{~m}^{2}$. Essas dimensões viabilizam a instalação da usina fotovoltaica, já que a área total necessária seria o correspondente a $25.000 \mathrm{~m}^{2}$, se considerarmos a dimensão de cada placa como 1,63 m.

No que tange à análise de viabilidade econômica, alguns aspectos técnicos precisam ser considerados. Estima-se que os módulos fotovoltaicos tenham vida útil de 25 anos, apresentando pouca necessidade de manutenção ao longo desse tempo. Dessa forma, o horizonte de tempo considerado para análise foi de 300 meses.

O custo dos painéis fotovoltaicos oscila de acordo com o tipo de material, dimensão e potência das placas, variando entre $R \$ 5.800$ e $R \$ 10.000$, por kW de potência. Para a fábrica têxtil, seriam utilizados painéis de silício policristalino, com dimensão de 1,63 e potência necessária correspondente a $3488,75 \mathrm{~kW}$, sendo o custo estimado de $\mathrm{R} \$ 5.800$ por kW de potência (SICES BRASIL, 2017).

Considerando que ao final de 25 anos, a usina de geração fotovoltaica terá depreciado o equivalente a $75 \%$ de seu valor inicial, para um horizonte de tempo de 300 meses, a depreciação mensal foi considerada 0,25\%.

Para fins de cálculo, foi considerado um aumento anual de 7\% na tarifa de energia elétrica, média dos reajustes nos anos de 2013, 2014 e 2015.

Dessa forma, os dados utilizados para cálculo do investimento no sistema fotovoltaico são apresentados na Figura 9. 
Figura 9 - Investimento no sistema fotovoltaico

\begin{tabular}{|lrr|}
\hline Custo do kWh industrial & RS & 0,43 \\
Aumento anual da tarifa & & $7 \%$ \\
Potência demanda em kW & & 3488,75 \\
Custo por kW de potência & RS & $5.800,00$ \\
Radiação média anual (kWh/m ${ }^{2}$.dia) & & $443,00 \%$ \\
Depreciação/mês & $0,25 \%$ \\
Total do investimento no sistema & RS 20.234.750,00 \\
\hline
\end{tabular}

Fonte: Os autores

Num primeiro momento, o investimento de mais de 20 milhões de reais em uma usina fotovoltaica parece inviável. No entanto, se considerarmos que pra tal modelo de investimento o payback é de pouco mais de sete anos, é possível perceber a rentabilidade do negócio. A partir do $7^{\circ}$ ano, a empresa passaria a obter retorno do investimento, e, considerando que os gastos atuais com energia elétrica giram em torno de $\mathrm{R} \$ 500.000,00$ mensais e que a tarifa energética industrial sofre reajuste anual de em média 7\%, a indústria economizaria um montante equivalente a $\mathrm{R} \$ 112.910 .267,00$ ao final da vida útil da usina, comprovando a rentabilidade do negócio.

Quanto à perspectiva ambiental, torna-se essencial a definição de um modelo de eficiência incorporado aos processos produtivos, de modo a reduzir os desperdícios e consequentes impactos ambientais provenientes dos mesmos.

Com base no perfil da indústria, acredita-se que o modelo de Ecoeficiência seja o mais viável de aplicação, visto que foram identificados diversos tipos de desperdícios em sua linha de produção: superprodução, estoque, espera, transporte, defeitos, movimentação e processamento. É sabido que todos esses tipos de desperdícios têm como consequência o aumento no consumo de energia e de outros recursos e um impacto ambiental relativo.

Um plano de ação voltado para Ecoeficiência poderá contribuir de forma a reduzir a quantidade de energia e outros insumos necessários à fabricação dos produtos, minimizar a dispersão de qualquer tipo de emissão tóxica decorrente do processo produtivo, maximizar o uso sustentável dos recursos naturais, aumentar a durabilidade dos produtos da empresa por meio da melhoria da qualidade e incentivar a reciclagem interna e externa dos seus produtos (BARBIERI, 2011). 
A instalação da usina fotovoltaica para abastecer a demanda da fábrica, além de economicamente viável, é uma alternativa com enorme viés ambiental. $\mathrm{O}$ baixo impacto ambiental e social dessa forma de geração de energia faz com que esta seja uma excelente opção de geração limpa e sustentável. Apesar do custo ainda relativamente elevado se comparado a outras fontes, os benefícios da geração fotovoltaica são muitos: redução das perdas por transmissão, redução de investimentos em linhas de transmissão e distribuição, não sendo necessária área física exclusiva para instalação da tecnologia fotovoltaica.

\section{CONCLUSÃO}

Com base nos estudos realizados, é possível compreender a importância da energia para a sociedade atual. Energia esta responsável por todas as transformações existentes no planeta, assim como pelo desenvolvimento econômico, tecnológico e social. Não é possível imaginar a vida sem energia e a falta desta pode colocar em risco nossa sobrevivência na Terra. Desse modo, é crucial compreendermos a necessidade de gerir um bem tão precioso.

Partindo dessa necessidade de agir, a indústria têxtil analisada tem grande potencial para alinhar interesses estratégicos, econômicos e socioambientais. A partir de indicadores de eficiência energética definidos seria possível verificar as fontes de maior consumo, assim como realizar uma análise sistemática por toda a fábrica, o que possibilitaria a criação de planos de ação a fim de mitigar perdas, não só nos setores de potencial consumo, mas em toda a organização.

Por meio das análises realizadas, foi possível determinar que o modelo de gestão ambiental que melhor se adequa à cultura da organização é a Ecoeficiência, sendo necessária uma atuação integrada de toda a equipe, incluindo os gestores, para reduzir os desperdícios a fim de obter resultados significativos, de modo a gerar um menor impacto ambiental.

A energia solar fotovoltaica foi considerada a melhor opção para geração alternativa de energia elétrica, considerando o cenário ao qual está inserida a Empresa Beta. Os fatores determinantes para a escolha foram a incidência solar média da cidade onde está localizada a indústria, com altos índices de insolação no ano todo, e a disponibilidade da matéria prima no Brasil, considerado o país com uma 
das maiores reservas de silício do mundo. Outro determinante foi o grande número de empresas atuantes no setor fotovoltaico em Minas Gerais, onde estão presentes aproximadamente $15 \%$ de todas as empresas do ramo no Brasil, o que estreita o contato com os fornecedores da tecnologia. Deste modo, ao final da análise de viabilidade econômica, foi possível perceber a rentabilidade do investimento, que traria retornos para a empresa a partir do oitavo ano, com lucro estimado em 120 milhões ao final da vida útil da usina fotovoltaica.

Acredita-se que o desenvolvimento deste estudo foi essencial para compreender a ligação existente entre o meio ambiente e os interesses econômicos cada vez mais desenvolvidos e discutidos nos cursos de engenharia. As análises feitas possibilitarão o desenvolvimento de trabalhos futuros em diferentes vertentes: Engenharia da Sustentabilidade, Modelos de Gestão Ambiental e Geração Fotovoltaica.

\section{REFERÊNCIAS}

ALDABÓ, R. Energia solar. São Paulo: Artliber Editora. 2002.

ARTIACH, T; LEE,D; NELSON,D; WALKER,J. The determinants of corporate sustainability performance. Accounting and Finance, v. 50, n.1, p.31-51, 2010. Disponível em < http://onlinelibrary.wiley.com/doi/10.1111/j.1467-

629X.2009.00315.x/epdf?r3_referer=wol\&tracking_action=preview_click\&show_checkout=1\& purchase_referrer=onlinelibrary.wiley.com\&purchase_site_license=LICENSE_DENIED>. Acesso em 24 abr. 2016.

AZAPAGIC; PERDAN. Indicators of sustainable development for industry: A general framework. Process Safety and Environmental Protection, v.78, n.4, p.243-261, 2000.

BARBIERI, J. C. Gestão ambiental empresarial. 3. ed. São Paulo: Saraiva, 2011. 376p.

BAUMGARTNER, R.J. Corporate sustainability performance: Methods and illustrative examples. International Journal of Sustainable Development and Planning, v.3, n.2, p.117-131, 2008.

BRASIL. Ministério de Minas e Energia. Agência Nacional de Energia Elétrica. Distrito Federal: ANEEL. 2016. Disponível em: < http://www.aneel.gov.br/>. Acesso em 13 dez. 2016.

BRASIL. Ministério de Minas e Energia. Anuário estatístico de energia elétrica: ano base 2014. Rio de Janeiro: EPE, 2015. Disponível em

$<$ http://www.epe.gov.br/AnuarioEstatisticodeEnergiaEletrica/Forms/Anurio.aspx>. Acesso em 23 abr. 2016.

CAMPOS, F.L.S; RAMOS, F.L; AZEVEDO, B.M. Análise de Viabilidade Econômica regulatória à crise de cooperativa de consumo de energia elétrica- o caso do setor elétrico 
brasileiro na segunda década do século XXI. Revista Produção Online, v.16, n.3, p. 966 987, Florianópolis, 2016. Disponível em < https://www.producaoonline.org.br/rpo/article/view/2305>. Acesso em 27 de fevereiro de 2017.

COMPANHIA ENERGÉTICA DE MINAS GERAIS. CEMIG. Disponível em < http://www.cemig.com.br/pt-br/Paginas/default.aspx>. Acesso em 13 de dezembro de 2016.

CONFEDERAÇAO NACIONAL DA INDÚSTRIA. A indústria em números. Distrito Federal: CNI, 2016. Ano 3. Número 3. Disponível em <http://arquivos.portaldaindustria.com.br/app/cni_estatistica_2/2015/02/11/165/Industria_Nu meros_mar2016_MOBILE.pdf>. Acesso em 28 mar. 2016.

CRESESB. Centro de referência para energia solar e eólica Sérgio Brito. Disponível em $<$ http://cresesb.cepel.br/index.php?section=com_content\&lang=pt\&cid=291 >. Acesso em 29 de janeiro. 2017

CRETON; STHEL. A ciência do aquecimento global. Rio de Janeiro: FAPERJ, 2011. $175 p$.

DUPONT, H.D; GRASSI, F; ROMITTI, L. Energias Renováveis: buscando por uma matriz energética sustentável. Revista Eletrônica em Gestão, Educação e Tecnologia Ambiental. Santa Maria, v.19, n-1, Ed. Especial, p. 70-81. Universidade Federal de Santa Maria. 2015. Disponível em < https://periodicos.ufsm.br/reget/article/view/19195>. Acesso em 29 de janeiro. 2017

GOLDEMBERG, J; LUCON, O. Energia, meio ambiente e desenvolvimento. 3. ed. rev. e ampl . São Paulo: EDUSP, 2011. 400p.

GREENPEACE. Revolução Energética: a caminho do desenvolvimento limpo. São Paulo: Greenpeace, 2010. 40p. Disponível em <

http://www.greenpeace.org/brasil/Global/brasil/report/2010/11/revolucaoenergeticadeslimpo. PDF>. Acesso em 04 fev. 2016.

HALLIDAY, D.; RESNICK, R.; WALKER, J. Fundamentos de física, volume 2: gravitação, ondas e termodinâmica. Rio de Janeiro: LTC, v. 8, 2009.

INTELIGÊNCIA DE MERCADO. Relatório setorial da indústria têxtil brasileira. São Paulo: IEMI, 2016. Disponível em < http://www.iemi.com.br/press-release-iemi-lancarelatorio-setorial-da-industria-textil-brasileira-2/>. Acesso em 28 mar. 2016.

IPCC. IPCC Expert Meeting on the future of the Task Group on data and Scenario Support for Impacts and Climate Analysis. Geneva: IPCC, 2016. Disponível em: http://www.ipcc.ch/pdf/supporting-material/EMR_TGICA_Future.pdf. Acesso em 02 maio. 2016.

MARQUES, M.C.S; HADDAD, J; GUARDIA, E.C. Eficiência energética: teoria e prática. 1. Ed. Universidade Federal de Itajubá: FUPAI. 2007. 244p.

MAY, P. H. Economia do meio ambiente. 2. ed. Rio de Janeiro: Elsevier, 2010. 379 p.

MIGUEL, P. A. C.; FLEURY, A. C. C. Metodologia de pesquisa em engenharia de produção e gestão de operações. Rio de Janeiro: Campus, 2012. v. 2 
MINAYO, M. C. S; SANCHES, O. Quantitativo-qualitativo: oposição ou complementariedade? Caderno de Saúde Pública da Escola Nacional de Saúde Pública da FioCruz. Rio de Janeiro: FioCruz, 1993.

NOBRE, C; REID, J; VEIGA, A.P.S. Fundamentos científicos das mudanças climáticas. São José dos Campos, SP. Rede Clima/ INPE. 2012, 44p. Disponível em < http://www.inpe.br/noticias/arquivos/pdf/fundamentos_cientificos_mc_web.pdf $>$. Acesso em 29 de janeiro de 2017.

OLIVEIRA, J.A; G,M; Q, G.A; C, R.L.RB; O, A.R; O, O.J. Identificação dos benefícios e dificuldades da produção mais limpa em empresas industriais do estado de São Paulo. Revista Produção Online, v.15, n.2, p. 458-481, Florianópolis, 2015. Disponível em < https://producaoonline.org.br/rpo/article/view/1751> . Acesso em 27 de fevereiro de 2017.

REGO, A; P.K. Lei complementar №140/11: Inovações em relação ao processo administrativo ambiental brasileiro. Ribeirão Preto: Universidade de São Paulo, 2013. $116 f$.

REIS, H; B.C. Os impactos da globalização sobre o meio ambiente: uma introdução à análise da comunicação social. Revista Contemporânea, v.1, n.4, p. 169-180, 2005. Disponível em < http://www.contemporanea.uerj.br/pdf/ed_04/contemporanea_n04_15_HeloizaBeatriz.pdf >. Acesso em 04 dez. 2015.

REIS, L; SANTOS, E. Energia elétrica e sustentabilidade: aspectos tecnológicos, socioambientais e legais. São Paulo: Manole, 2014. 262p

REN 21. Renewable Energy Policy Network for the 21st Century. National Technical University of Athens. 2015. Disponível em < http://www.ren21.net/wpcontent/uploads/2016/06/GSR_2016_Full_Report.pdf>. Acesso em 29 de janeiro de 2017.

ROCHA, J.M. A gestão dos recursos naturais: uma perspectiva de sustentabilidade baseada nas aspirações do "lugar". Disponível em: http://www.ambiente.sp.gov.br/wpcontent/uploads/cea/Texto_Rocha.pdf. Acesso em 06 de junho. 2016.

RODRIGUES, A.M; ZEVIANE, C.H; REBELATO, M.G; BORGES, L. Avaliação de desempenho ambiental industrial: elaboração de um referencial metodológico. Revista Produção Online, v.15, n.1, p. 101-134, Florianópolis, 2015. Disponível em < https://producaoonline.org.br/rpo/article/view/1719 > . Acesso em 27 de fevereiro de 2017.

SALUM, L.J.B. Energia eficaz. Belo Horizonte: CEMIG, 2005. 360p.

SANTOS, P.R.G; FLORENTINO, M.C.C; BASTOS, J.L.C; TREVISAN, G.V. Fontes Renováveis e não renováveis geradoras de energia elétrica no Brasil. VIII MICTI. IFC: Instituto Federal Catarinense: 2015. Disponível em < http://eventos.ifc.edu.br/wpcontent/uploads/sites/ >. Acesso em 29 de janeiro de 2017.

SICES BRASIL. Disponível em < http://www.sicesbrasil.com.br/>. Acesso em 13 de dezembro de 2016.

SILVA, B.O.S. A importância da sustentabilidade para o desenvolvimento organizacional e sua influência na engenharia de produção. Trabalho de Conclusão de Curso. (Graduação em Engenharia de Produção) - Instituto de Ciências Exatas e Aplicadas. João Monlevade: Universidade Federal de Ouro Preto, 2015. 
SILVA, R.W.C; PAULA, B.L. Causa do aquecimento global: antropogênica versus natural. Terrae Didática v.5, n.1, p. 42-49, 2009. Disponível em <

https://www.ige.unicamp.br/terraedidatica/v5/pdf-v5/TD_V-a4.pdf >. Acesso em 28 de fevereiro de 2017.

TONIN, G. A gestão de energia elétrica na indústria: suprimento e uso eficiente. Dissertação (Mestrado) - Universidade de São Paulo, São Paulo. 2009. Disponível em < www.teses.usp.br/teses/disponiveis/.../Dissertacao_Gilberto_Tonim.pdf >. Acesso em 06 nov. 2015.

TORRES, L.V. Gestão de custos na cafeicultura: uma experiência na implantação de projetos. VII Congresso Brasileiro de Custos. Recife, PE. Agosto de 2000. Disponível em $<$ https://anaiscbc.emnuvens.com.br/anais/article/view/3066>. Acesso em 29 de janeiro de 2017.

TRIERWEILLER, A; CAMPOS, L.M.C; CARVALHO, D.N; SANTOS, D.H.S; BORNIA, A.C; PEIXE, B.C.S. Gestão Ambiental: levantamento da produção científica brasileira em periódicos de engenharia de produção. Revista Production, v.24, n.2, p.435-450, 2014. Disponível em <http://dx.doi.org/10.1590/S0103-65132013005000051>. Acesso de 04 mai. 2015.

YIN, R.K. Estudo de caso: planejamento e métodos. 2. ed. Porto Alegre. Editora: Bookmam. 2001.

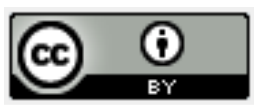

Artigo recebido em 02/03/2017 e aceito para publicação em 10/10/2017

DOI: http://dx.doi.org/10.14488/1676-1901.v18i1.2762 